\title{
Fetal Growth Retardation And Its Relationship To Maternal Blood Lead Levels, Antioxidants And Pregnancy Induced Hypertension
}

\author{
Ragab H. EL-Yamani* and Ahmed E. Karim** \\ * Obstetric and Gynecology Dept. Faculty of Medicine, Al-Margab University, Great \\ Socialist People's Libyan Arab Jamahiriya and **Biochemistry Dept., National research \\ center, Cairo, Egypt.
}

\begin{abstract}
Lead intoxication in human being has been documented since the second century BC and its deleterious effects continue to be a major health hazard for the population, it is demonstrated that lead exposure might decrease the defense mechanism of the cell to the oxidative stress, and therefore, elevate the reactive oxygen species (ROS) generation which enhance vascular reactivity. Since vitamin E (Vit. E) and vitamin C (Vit. C) are natural antioxidants, changes in their status may reflect alterations in free radical production rate and their concentrations are biological markers of oxidative stress. This study was conducted to determine the relationship between maternal blood lead levels and the antioxidants Vit.E and Vit.C in a step to understand the mechanism of action of lead and its possible influence on maternal blood pressure and fetal growth at the lower community exposure levels.

The study included, 42 patients with pregnancy induced hypertension (PIH) with or without proteinuria, 31 patients with fetal growth retardation (FGR) and 23 women with uncomplicated pregnancy. We demonstrated that, the maternal blood lead levels were significantly high in the PIH $(30.5 \pm 0.978 \mu \mathrm{g} / \mathrm{dl})$ and FGR groups $(28.87 \pm 1.21 \mu \mathrm{g} / \mathrm{dl})$ as compared with the uncomplicated pregnancy group $(17.82 \pm 110 \mu \mathrm{g} / \mathrm{dl})$ at $\mathrm{P} \leq 0.001$ Vit.E concentrations were significantly lower in both PIH and FGR $(0.941 \pm 0.033 \mathrm{mg} / \mathrm{dl}$ and $0.866 \pm$ $0.055 \mathrm{mg} / \mathrm{dl}$ respectively) when compared with normal group $(2.00 \pm 0.085 \mathrm{mg} / \mathrm{dl})$. Regarding Vit.C in the 2 studied groups there was significantly low levels in PIH group $(0.772 \pm 0.030$ $\mathrm{mg} / \mathrm{dl}$ and FGR $(0.847 \pm 0.039 \mathrm{mg} / \mathrm{dl})$ in comparison with control group $(1.23 \pm 0.06 \mathrm{mg} / \mathrm{dl})$. We observed significant negative correlation between maternal blood lead levels and Vit.E in PIH and FGR group. A significant negative correlation was also observed between maternal lead levels and Vit.C in both studied groups.

We concluded that high blood lead levels in pregnancy are associated with low Vit.E , Vit.C, FGR and PIH. Such association or relationship could not be causal and more longitudinal studies are needed to confirm the link between lead, lipid peroxidation, antioxidants and pregnancy complications. This study may help in raising our consciousness of our environment and the need to protect us. The lack of effective and safe treatments for low-level intoxication has to promote environmental intervention to control different sources of lead to reduce lead burden among women and their newborns and to protect the fetus from other intrauterine toxic exposure that might be injurious.
\end{abstract}

\section{Introduction}

Women are exposed increasingly to a variety of chemicals; including heavy metals, in the work place and environment (Guillette and Guillette 1996 and Sharara et al., 1998). The chemicals may alter normal cellular processes such as differentiation, mitosis, meiosis, programmed cell death, migration, intracellular communication, DNA repair, and mitochondrial dysfunction (Mattison, 1983). These 
alterations could result in abnormal tissue gro-wth, function, or death. In pregnant women, the susceptibility of fetal tissues is determ-ined by stage of development of the embryo and the fetus and the duration or often the cumulative amount of exposure (Sharara et al., 1998).

Lead is nonessential metal and a major environmental toxicant. Lead intoxication in human being has been documented since the second century B.C. (Perazella, 1996) and its deleterious effects continue to be a major health hazard for the population (Perazella, 1996 and Hernandez -Avila et al., 1997). Human and wildlife are exposed to lead in water, food, soil and air. In USA it is estimated that > 42 millions people are exposed excessively to lead through drinking water and that up to $52 \%$ of residential homes contain unacceptable levels of lead in paint (Agency for Toxic Substances and Disease Registry 1993). In addition to the exogenous exposure to lead from the environment, millions of women in childbearing period have been exposed to excessive amount of lead as children, some of which is still stored in the skeleton because of the 10-30 years half life of lead in bone (Silbergeld, 1991). It is confirmed that lead mobilized from skeletal stores at an accelerated rate and contributes significantly to blood lead levels late in pregnancy. Increases of $>20 \%$ during pregnancy have been detectable even in subjects with low blood lead levels. It is shown that $45 \%$ to $75 \%$ of blood lead in mothers of childbearing age comes from tissue stores.

Resorption of the skeleton was probably the overriding mechanism for lead mobilization and is the most likely mechanism to explain the increase in blood lead levels during the second half of pregnancy (Gulson et al., 2002).

Since there is no known maternalfetal barrier to lead, it readily crosses the placenta and levels below $5 \mu \mathrm{g} / \mathrm{dl}$ were shown to cross the placenta to the fetus (Granziano et al., 1990). Furthermore, the levels of lead in cord blood are highly correlated with that in maternal blood. So maternal lead is a source of exposure to the developing fetus which may have an adverse effect on pregnancy outcomes and the factors influencing maternal blood lead levels also contribute to fetal lead burden (Goyer 1990 and Bellinger et al., 1991)

Although the adverse effects on pregnancy outcomes at this levels of lead exposure in the work place has been recognized for years, there is uncertainty regarding the impact of exposure at the lower community exposure levels commonly encountered today. Lead has been linked to an increased risk of spontaneous abortion, miscarriage, fetal growth retardation (FGR) or preterm labor (Lindbohm et al.,1992 and Andrews, et al., 1994).

The potential explanation for such apparent association is many and complex. It is unlikely that this is simply a chance association and it could not be explained solely by differing socioeconomic status (Recknor et al., 1997). Lead inhibits enzymes, alter cellular calcium metabolism, stimulate synthesis of binding proteins in kidney, brain, and bone; and slow nerve conduction (Lockitch, 1993). More recently, it was demonstrated that, lead exposure might decrease the defense mechanism of the cell to the oxidative stress and therefore elevate the reactive oxygen species (ROS) generation. Supplementation with vitamin E (Vit.E) and/or vitamin C (Vit.C) inhibits lead induced ROS generation (Hsu et al., 1998). ROS has been shown to stimulate vascular smooth muscle growth and proliferation and enhance vascular reactivity (Rao and Berk, 1992). Chronic exposure to low lead levels resulted in sustained hypertension in human and experimental animals, coupled with increased ROS generation (Vaziri et al., 1997 and Ding et al., 2003).

Natural antioxidants, Vit.E (tochopherols), Vit.C (ascorbic acid) and beta-carotene possess a wide range of properties. Vit. E restores normal phagocytic functions (Hill et al., 1993), and it is efficacious in glutathione synthetase deficient patients (Boxer, et a., 1979). Vitamin E may reduce corticosteroid levels induced by stress (Watson and Peiro, 1982) and together with vitamin $\mathrm{C}$ and $\mathrm{A}$ has been considered as a cancer preventing agent 
(Watson \& Leonard, 1986) as well as a free oxygen radical scavengers in several disease conditions characterized by raised oxidation processes (Rimm et al., 1993). Vit.E and Vit.C prevent lipid peroxidation, reduce platelet aggregation, modulate prostaglandin and leukotriene synthesis, and reduce inflammation (Enstrom et al., 1992). Several epidemiologic trials suggest that populations with high intake of Vit.E. have a lower risk of vascular disease (Gey et al.,2001). Since Vit.E and VitC are antioxidants, changes in their status may reflect alteration in free radical production rate and their concentrations, so they are good biological markers of oxidative stress (Watson, 1990).

This study was conducted to determine the relationship between maternal blood lead levels and the antioxidants Vit.E and Vit.C in a step to understand the mechanism of action of lead and its influence on maternal blood pressure and fetal growth.

\section{Subjects And Methods:}

This study was conducted from October 1999 to October 2002 on 42 patients with pregnancy-induced hypertension (PIH), 31 patients with fetal growth retardation (FGR) and 23 women with uncomplicated pregnancies. All groups had regular antenatal care and singleton pregnancy at El-Khoms general hospital.

Information on social, biological and clinically relevant characteristics of each mother was obtained. We ascertained parity, gravidity, age, educational level, prepregnancy weight and current weight and height. Full clinical examination including blood pressure and full obstetric examination. Gestational age (GA) of the participants was $\geq 34$ weeks. It was calculated from last menstrual period and confirmed by ultrasonography (U/S) done before 18 weeks of gestation. Most of them were of the same socioeconomic status and educational level. Subjects with diabetes, genital infection, +ve TORCH screen, urinary tract infection, sickle cell anemia, thalassemia, hemoglobin $\mathrm{C}$, smokers, or mothers with history or family history of malformed baby and /or malformed baby in current pregnancy were excluded.

$\mathrm{PIH}$ was defined as blood pressure of $\geq$ $140 / 90 \mathrm{mmHg}$ (in two occasions) with or without proteinuria after 20 weeks of pregnancy, preeclamptic toxemia (PET) was divided into mild if systolic blood pressure 140-155 $\mathrm{mmHg}$ and diastolic 90 to $105 \mathrm{mmHg}$ with proteinuria +1 or +2 and as severe if systolic blood pressure $\geq 160$ $\mathrm{mmHg}$ and diastolic $\geq 110 \mathrm{mmHg}$ with proteinuria +3 .

Fetal growth retardation was diagnosed clinically by uterine fundal level and serial abdominal U/S; biparietal diameter (BPD), femur length (FL) and abdominal circumference (AC) were measured to calculate GA and fetal weight which compared to the previous findings.

\section{Biochemical measurements:}

Venous blood samples, without venous occlusion, were obtained from each subject in a fasting state between 9:00 and 10: 00 AM was analyzed for blood counts, hemoglobin, urea, creatinine, albumin, uric acid and glucose. In addition TORCH screen, sickle cell test, hemoglobin electrophoresis, urine analysis and urine culture and high vaginal swab were done.

Ascorbic acid assay was performed by spectrophotometer in the plasma obtained from heparinized blood within 1 hour of collection. Plasma was separated and stored at $-80^{\circ} \mathrm{C}$ to be used for estimation of Vit.E. Alpha tochopherol concentration was assayed by high-performance liquidchromatography, using a fluorescence detector (Huo et al., 1996).. A simple monophasic extraction with water miscible solvent followed by the direct injection of an aliquot of the extract on the column has been used (Ohruvall et al., 1993).

For trace element determination, blood was anticoagulated with a traceelement-free heparin in polypropylene tubes, which were also free of trace elements. The whole blood was selected for analysis because most circulating lead is 
carried in the erythrocytes (West et al., 2004). All samples were analyzed for total lead concentrations using flameless atomic absorption spectrophotometry (PerkinElmer model 503 with GA-2100 Heated Graphite Atomizer, Perkin-Elmer).

\section{Results:}

Ninety-six women were included in this study, 31 patients (32.29\%) with FGR an 42 patients $(43.75 \%)$ with $\mathrm{PIH}$ and 23 women (23.29\%) with uncomplicated pregnancy (control group). Results of the present study are prescribed in seven figures. Blood lead levels were observed to be significantly higher (mean \pm S.E.) in both FGR $(28.87 \pm 1.21 \mu \mathrm{g} / \mathrm{dl})$ and PIH $(30.50$ $\pm 0.978 \mu \mathrm{g} / \mathrm{dl}$ ) groups, compared to the control $(17.82 \pm 1.10 \mu \mathrm{g} / \mathrm{dl})$ Fig. (1).
On the other hand plasma Vit. E concentrations were significantly lower in both FGR and PIH groups $(0.86 \pm 0.055$ $\mathrm{mg} / \mathrm{dl}$, and $0.94 \pm 0.033 \mathrm{mg} / \mathrm{dl}$ ) respectively when compared with control group $(2.00 \pm 0.085 \mathrm{mg} / \mathrm{dl})$ (Fig. 2).

Regarding the levels of Vit.C, in the two studied groups, there was a significant decrease in FGR groups $(0.84 \pm 0.39 \mathrm{mg} / \mathrm{dl})$ and $\mathrm{PIH}(0.77 \pm 0.030 \mathrm{mg} / \mathrm{dl})$ in comparison to control group $(1.23 \pm 0.06 \mathrm{mg} / \mathrm{dl}) \mathrm{Fig}$.

The study of the relation between maternal lead levels and Vit.E showed a significant negative correlation in FGR and $\mathrm{PIH}$ groups (Fig. 4 and 5), $\mathrm{r}=0.361$, $\mathrm{P}<0.001$ for $\mathrm{FGR}$ and $\mathrm{r}=0.523, \mathrm{P}<0.001$ for $\mathrm{PIH})$.

Also a significant negative correlation was observed between maternal lead levels and Vit.C in both PGR and PIH (Fig. 6 and 7), $(r=0.303 \mathrm{p} \leq 0.01$ and $\mathrm{r}=0.421 \mathrm{P} \leq 0.001$, respectively).

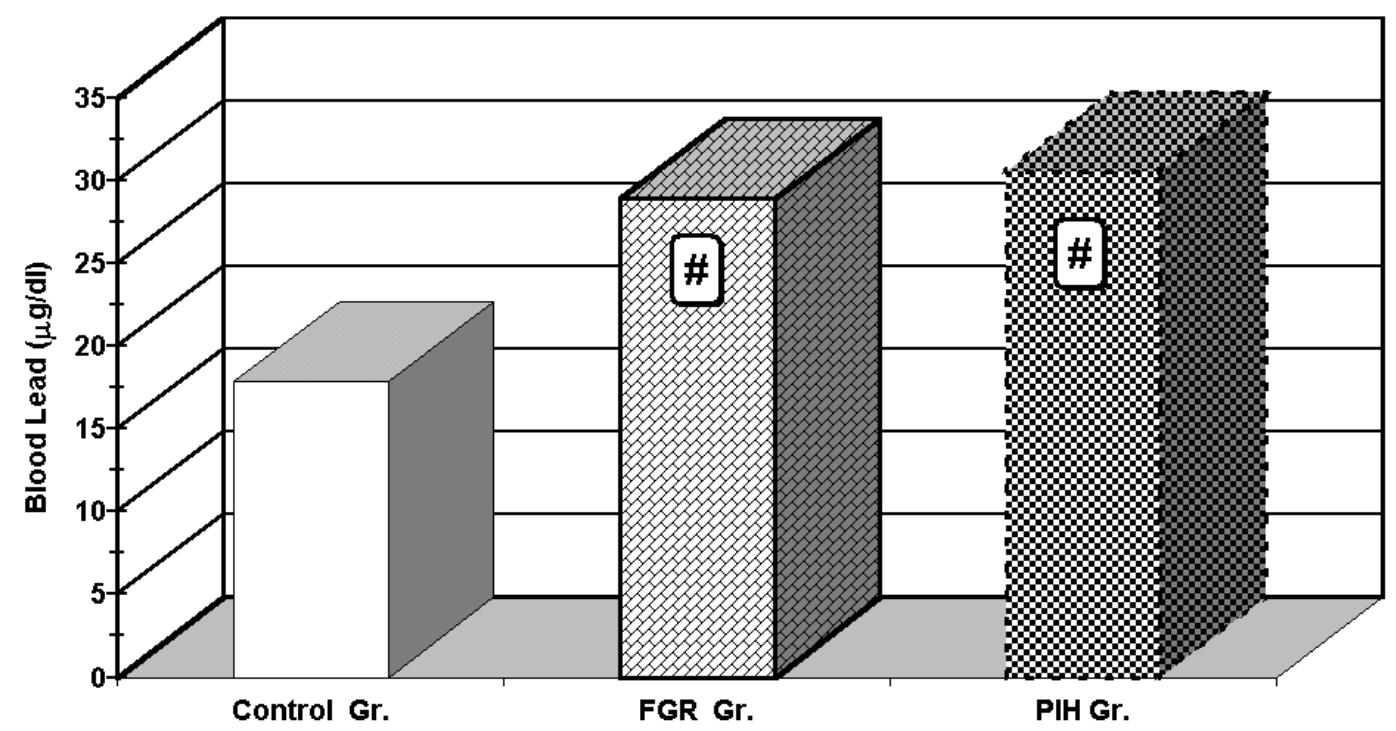

Fig. (1) : Maternal blood level of lead in Control, FGR and PIH groups.

\# Significant change from the Control Gr. at $p<0.001$ 


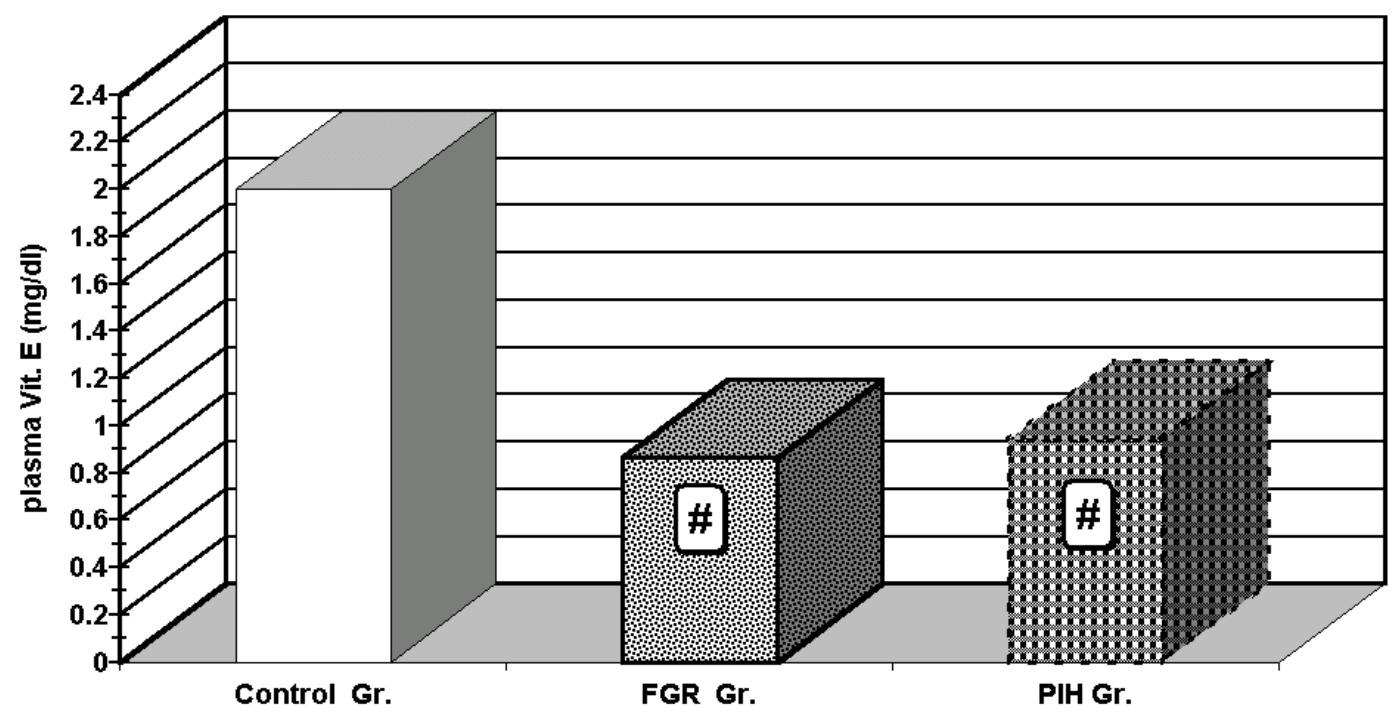

Fig. (2) : Maternal plasma level of plasma Vit. E in Control, FGR and PIH groups.

\# Significant change from the Control $\mathrm{Gr}$. at $\mathrm{p}<0.001$

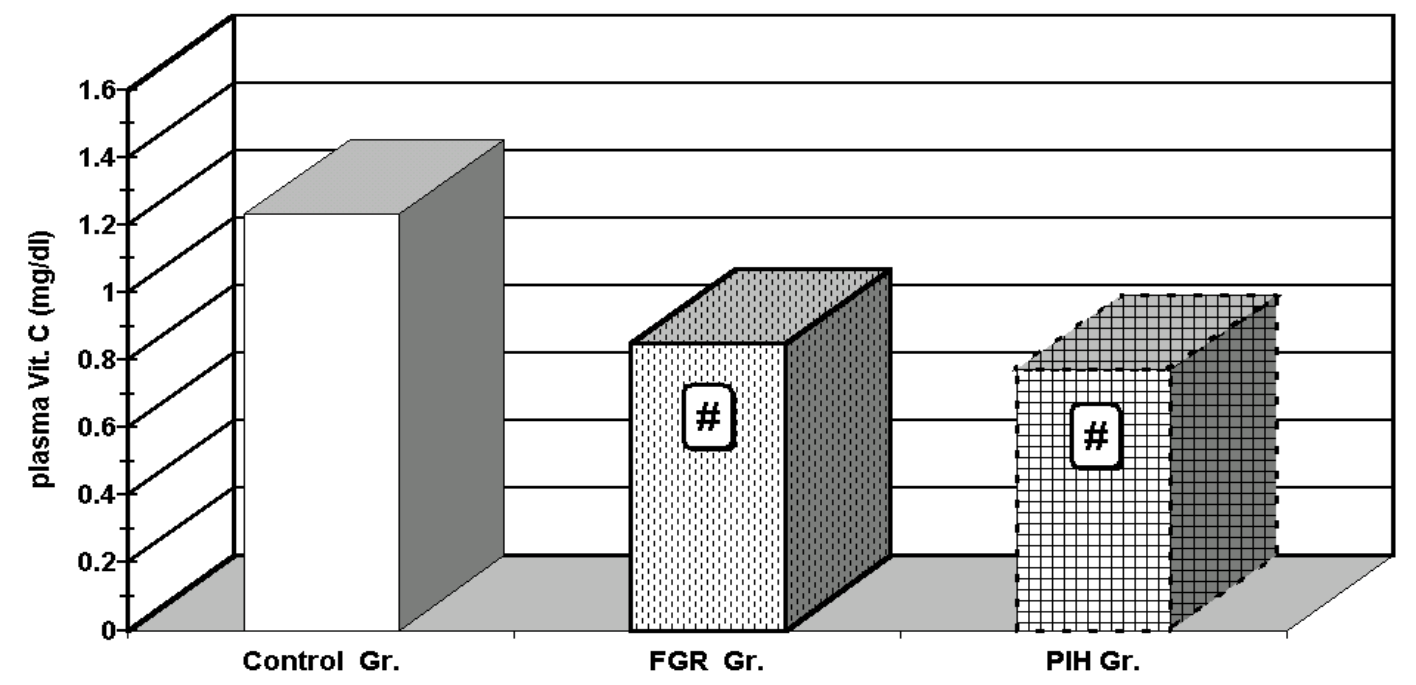

Fig. (3) : Maternal plasma level of plasma Vit. C in Control, FGR and PIH groups.

\# Significant change from the Control Gr. at $p<0.001$ 


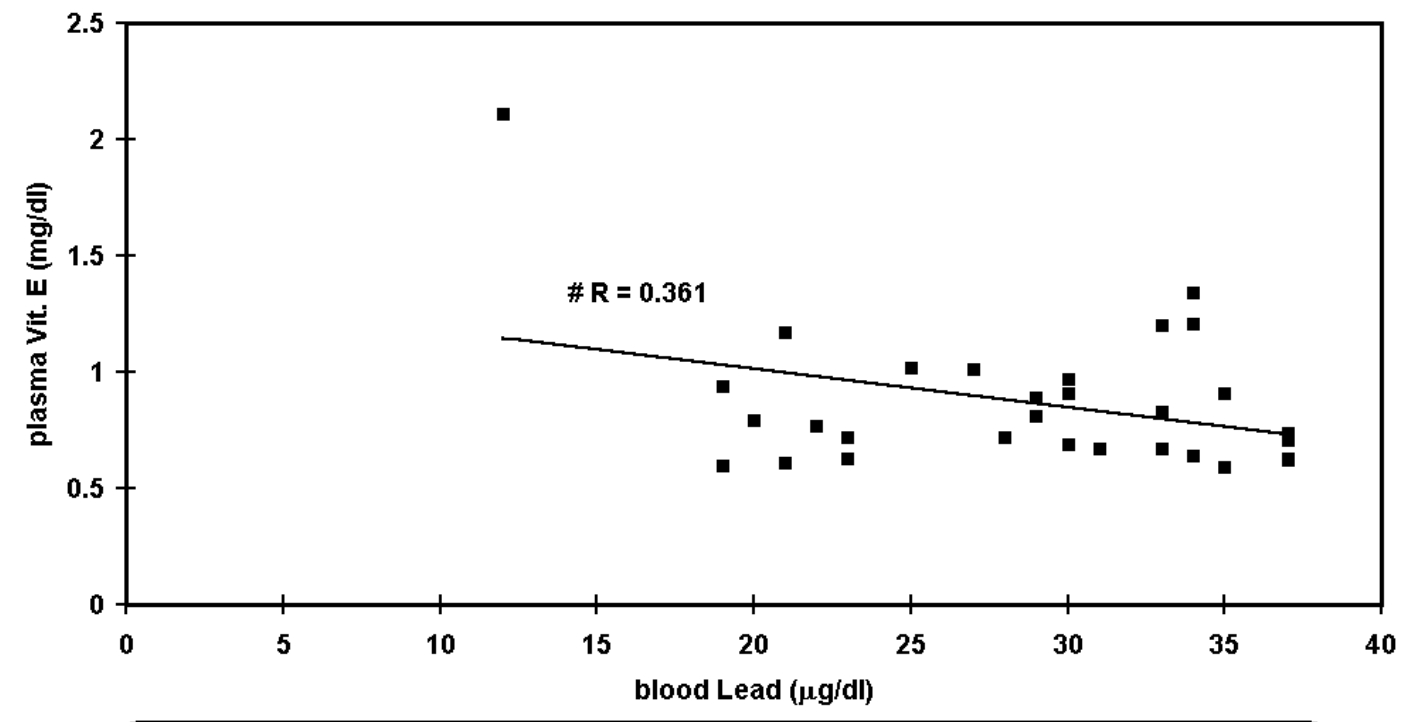

Fig. (4) : The correlation between maternal blood lead and maternal Vit. $E$ in the FGR group

\# Significant correlation at $p \leq 0.001$

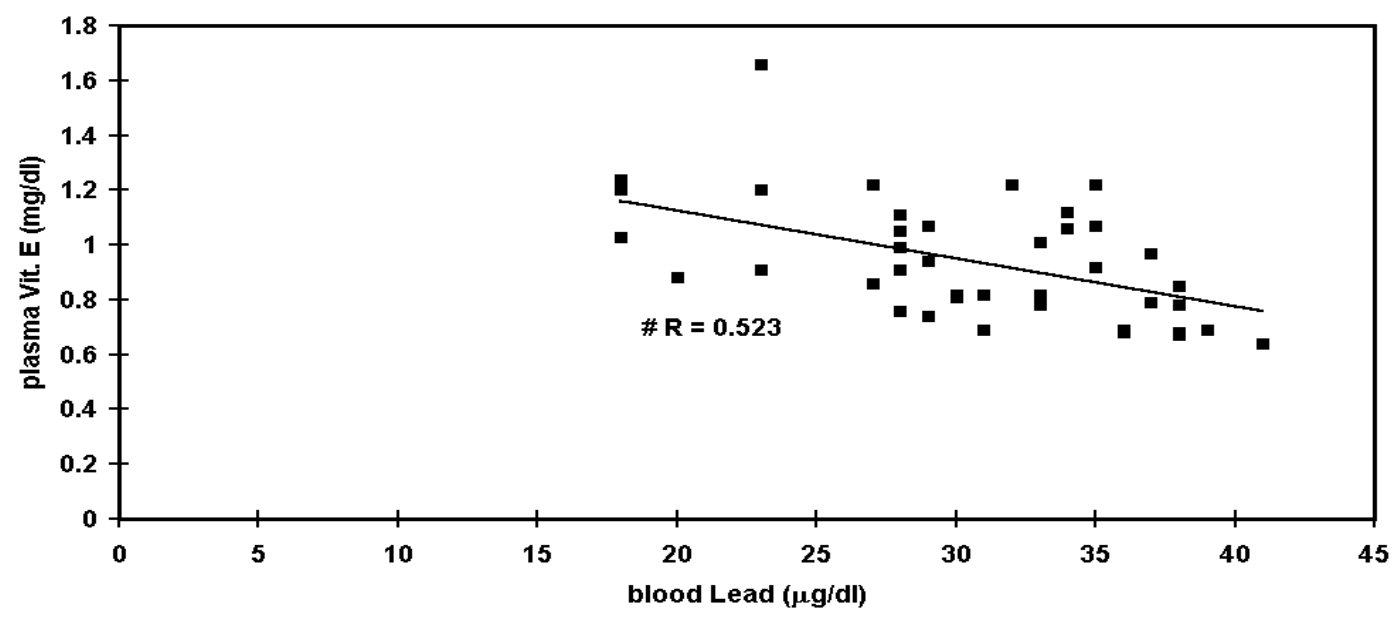

Fig. (5) : The correlation between maternal blood lead and maternal Vit. E in the PIH group

\# Significant correlation at $\mathrm{p} \leq \mathbf{0 . 0 0 1}$ 


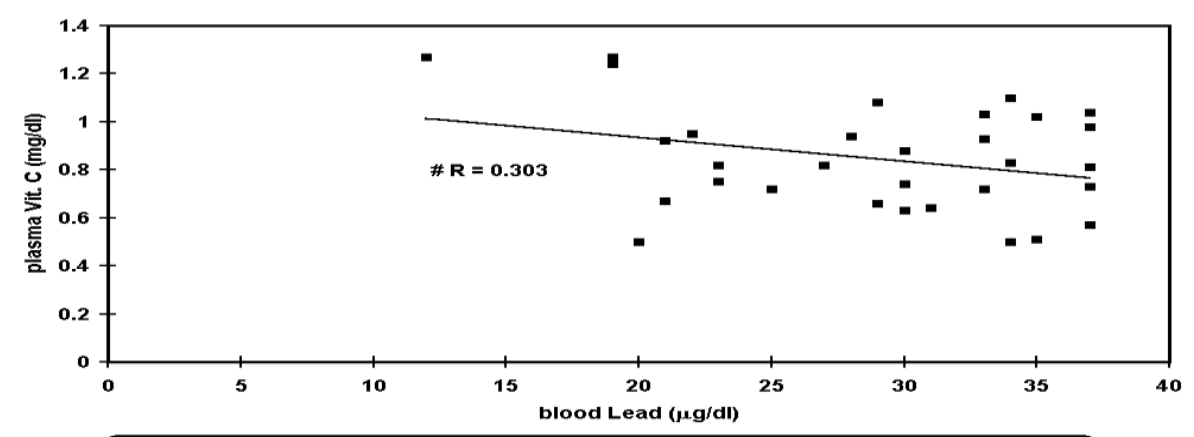

Fig. (6) : The correlation between maternal blood lead and maternal plasma Vit. $C$ in the FGR group

\# Significant correlation at $p \leq 0.05$

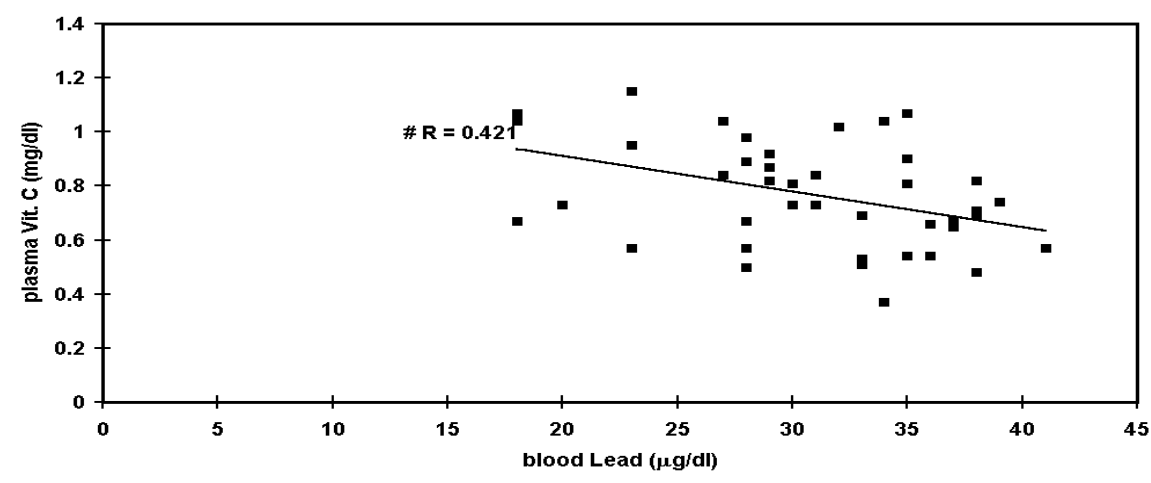

Fig. (7) : The correlation between maternal blood lead and maternal plasma Vit. $C$ in the PIH group

\# Significant correlation at $p \leq 0.001$

\section{Discussion:}

To our knowledge, this is the first study in pregnant women to determine the relationship between maternal blood lead and the natural antioxidants (Vit.E and Vit.C) and the hypertensive disorders in pregnancy. In this study it is observed that, blood lead levels of women with PIH was significantly higher than women with uncomplicated pregnancy $(\mathrm{P} \leq 0.001)$.

While both Vit.E and Vit.C were significantly lower in PIH group with a significant inverse correlation between these antioxidants and maternal blood lead levels. In accordance with our finding, Bogden et al., (1995), demonstrated that, lead exposure in pregnant rats, resulted in hypertensive disorders during the 3rd trimester of pregnancy which is consistent with the timing of PIH in women that usually develops during the 3rd trimester and the timing of increased mobilization of lead from maternal skeleton during the second half of pregnancy ( Gulson et al., 1997).

Toxic lipid peroxidation products may cause endothelial cell damage, which is believed to be a central feature in the pathogenesis of pregnancy induced hypertensive disorders (Friedman et al., 1991). Lipid peroxidation assessed by the appearance of conjugated dienes and malondialdehyde was significantly increased in the hypertensive patients as compared with control patients. The products of lipid peroxidation have effect on the vascular function and showed correlation to the level of blood pressure (Uotila et al., 2003). It is observed that increased level of lipid peroxides and reduced antioxidant status in the placenta and plasma clearly demonstrate the presence of oxidative stress in PET (Mutiu-Turkoglu et al., 1998). So 
an oxidant/antioxidant imbalance has been suggested among the pathogenic factors involved in PIH and Vit.E is one of the most important antioxidant body components. However, in cases with already established disease, Vit.E does not improve fetal outcome in severe PIH and it does not show favorable effect on maternal hypertension and proteinuria (Stratta et al., 1994).

It is demonstrated that, lead exposure might decrease the defense mechanism of the cell to the oxidative stress and significantly increases the peroxidative reactions and therefore elevates ROS (Chaurasia and Kar, 1997 and Hsu et al., 1998). Chronic exposure to low lead levels resulted in sustained hypertension in human and experimental animals, coupled with increased ROS production (Vaziri et al., 1997 and Ding et al., 1998) .On the other hand, a defense system, consisting of antioxidative free radical scavenging molecules and enzymes, serves to control lipid peroxidation (Hubel et al., 1989). The administration of the potent antioxidant lazaroid abrogated the lead-induced hypertension, so it is speculated that leadinduced hypertension may be caused by ROS, which enhance vascular reactivity (Vaziri et al., 1997). These data support our findings of significantly high maternal blood lead levels with concomitant significantly low Vit.E and Vit.C concentration in-patients with PIH as compared with uncomplicated pregnancy group. The observed low Vit.E and Vit.C concentrations in patients with PIH could be explained by the exhausted antioxidative system caused by the associated high blood lead levels since the participants were homogeneous in term of socioeconomic status, more or less of the same educational level and all of them shared antenatal care programs.

In this study we observed that, maternal blood lead levels of mothers with FGR was significantly higher than that in mothers with uncomplicated pregnancies $(\mathrm{P} \leq 0.001)$ coupled with significantly low concentrations of Vit.E and Vit.C. This is in accordance with prior studies in laboratory animals and children that suggested that lead might reduce linear growth and weight gain during development (Hammond et al., 1993 and Bogden et al., 1995).

Recknor et al., 1997 also observed a positive relationship between LBW and high maternal blood lead levels, while West et al., (1994) could not find a correlation between LBW and high blood lead levels except after elimination of subjects with genital infection from analysis and they explained these findings by the fact that genital infection increased the risk of LBW by deflecting available Vit.C in reducing lead toxicity in these women.

Other studies (Kimmel et al., 2000) do not show an effect of lead on fetal weight. The differing results of the various studies could be explained at least in part by the difference in dietary calcium (Bogden et al., 1995). Vit.E and Vit.C and/or the nonexclusion of other factors influencing fetal growth (West et al., 1994).

The lead-induced FGR could be explained by concomitant and significant low Vit.E and Vit.C in this group as compared to uncomplicated group $(\mathrm{P} \leq$ $0.001)$. This is in accordance with the findings of Jiang and Shao (1994) who observed that serum level of Vit.E late in pregnancy with FGR is only half as that of controls and Vit.E concentrations in the mothers correlated positively to several indicators reflecting infant growth with multiple stepwise regression analysis. Furthermore Von-Mandach et al. (1993) demonstrated lower maternal levels of Vit.E and Vit.C in abnormal pregnancy including LBW. In addition, the increase in ROS generation as a result of high blood lead levels and low natural antioxidants (Vit.E and Vit.C), observed in this group, with its effect on vascular reactivity (Vaziri et al., 2002) may decrease the uteroplacental blood flow and result in FGR. Richter et al. (1997) demonstrated significantly high lead levels and lysozyme values in placenta of LBW pregnancies as compared to the normal group which may indicate local effect of lead on the placenta of growth retarded fetuses.

We conclude that, high lead levels in pregnancy are associated with low Vit.E and Vit.C and FGR and PIH. Such 
association or relationship may not be causal and more studies are needed to determine more details to understand the mechanism of actions of lead and to confirm the link between lead, lipid peroxidation, antioxidants, and pregnancy complications.

This study may help in raising our consciousness of our environment and the need to protect us. In the future, obstetrician, health care professionals and basic scientists need to work together to clarify the problem of lead exposure on the reproductive health of the mother with use of well-defined endpoints, larger sample size, and adequate methodology.

The lack of effective and safe treatments for low-level intoxication has to promote environmental intervention to control different sources of lead to reduce lead burden among women and their newborns and to protect the fetus from other intrauterine toxic exposure that might be injurious.

\section{References:}

1. Agency for Toxic Substances and Disease Registry (1993): Toxicological profile for lead. Washington, D.C.: US department of Health and Human Services.

2. Andrews, K.W.; Savitz, D.A. and HertzPicciotto I (1994): Prenatal lead exposure in relation to gestational age and birth weight: a review of epidemiologic studies Am. J. Ind Med. 26: 13.

3. Bellinger D., Sloman J.; Leviton, A.; Rabinowitz, M., Needlman, H.; and Waternaux C. (1991): Low lead level exposure and children's cognitive function in the preschool years. Pediatrics. 87: 219.

4. Bogden, J.D., Kemp, F.W, Han, S.; Murphy, M.; Fraiman, M. Czerniach, D.; Flynn, C.J. Banua, M.L.; Scimone, A, Castrovilly, L and Gertner, S.B. (1995): Dietary calcium and lead interact to modify maternal blood pressure, erythropoesis, and fetal and neonatal growth in rats during pregnancy and lactation. J. Nutr. 125: 990.

5. Boxer, L.A, Oliver S.O, Speilberg, J.M. Allen J.M. and Shulman J.D. (1979): Protection of granulocytes by vit. E in glutathione synthetase deficiency. New Eng. J. Med. 301: 901-905.

6. Chaurasia, S.S and Kar: (1997): A. protective effects of vitamin E against lead -induced deterioration of membrane associated type -I iodothyronine Smonodeiodinase activity in male mice. Toxicology. 124: 203.

7. Ding, Y; Vaziri, N.D and Gonick, H.C. (2003): Lead-induced hypertension. II Response to sequential infusions of Larginine, superoxide dismutase, and nitroprosside. Environ Res., 7: 107.

8. Enstrom, J.E.; Kanm, L.E, and Klein, M.A. (1992): Vitamin $C$ intake and mortality among a sample of the United States Population. Epidemiology. 3: 194-202.

9. Friedman, S.; Taylor, R, and Roberts, J. (1991): Pathophysiology of preeclampsia. Clin. Perinatal. 18: 661.

10. Gey, F.K.; Puska P., Jordon, P. and Moser, U.K. (2001): Inverse correlation between plasma vitamin $\mathrm{E}$ and mortality from ischemic heart disease in crosscultural epidemiology. Am. J. Clin. Nutr. 53: 326-345.

11. Goyer, R.A. (1990): Transplacental transport of lead. Environmental Health perspectives. 89: 101.

12. Granziano, J.H.; Popovac D.; FactorLitvak, P., Shrout P.; Kline, J.; Murphy, M. J.; Zhao, Y., Mehmeti, A.; Ahmedi and, Rajovic, B., Zvicer Z.; Nenezic C.U., Lolacono N.J. and Stein, Z. (1990): Determination of elevated blood lead during pregnancy in a population surrounding lead smelter in Kosovo, Yugoslavia. Environmental Health Prospective. 89: 95.

13. Guillette, L.J. and Guillette, E.A. (1996): Environmental contamination and reproductive abnormalities in wild life: Implications for public health? Toxicol Ind. Health. 12: 537.

14. Gulson B.L.; Jameson C.W.; Mahaffey K.R. Mizon K.J., Korsch M.J. and Vimpani G. (2002): Pregnancy increases mobilization of lead from maternal skeleton J. Lab. Clin. Med 130: 41.

15. Hammond, P.B.; Minnema, D.J. and Succop P.A. (1993): Reversibility of leadinduced depression of growth. Toxicol. Appl. Pharmacol. 123: 9.

16. Hernandez-Avila, M.; Sanin, L.H.; Romieu, I.; Palazuelos, E.; Tapia-Conger R.; Olaiz, G.; Rojas, R. and Navarrete, J. (1997): Higher milk intake during pregnancy is associated with lower maternal and umbilical cord lead levels in postpartum women. Environmental Research. 74:116.

17. Hill, H.R.; Augustine, M.L, Rallison, M.L, and Santos, J.L. (1993): Defective 
monocyte chemotactic responses in diabetes mellitus. J. Clin. Immunology. 3: 70-77.

18. Hsu-P.C.; Liu-M.Y.; Hsu-C.C.; ChenL.Y. and Guo-YL. (1998): Effects of vitamin $\mathrm{E}$ and /or $\mathrm{C}$ on reactive oxygen species -related lead toxicity in the rat sperm. Toxicology. 128: 169.

19. Hubel, C.; Robertts, J.; Taylor, R.; Musci, T.; Rogers, G. and McLanghlin, M. (1989): Lipid peroxidation in pregnancy; new perspectives on preeclampsia. Am. J. Obstet. Gynecol.161: 1025.

20. Huo, J.Z.; Nelis, H.J. and Lavens, P. (1996): Determination of vitamin $\mathrm{E}$ in aquatic organisms by high performance liquid chromatography with fluorescence detection. 242: 123-128.

21. Jiang Y. and Shao, Y.E. (1994): Case control study on intrauterine growth retardation and vitamin nutritional status in late pregnancy Chunz-Hau-Yu-Fang-IHsueh-Tsa-Chin. 28: 210.

22. Kimmel, C.A, Gant L.D, Sloan C and Gladen B.C.(2000): Chronic low-level lead toxicity in the rat. Toxicol. App. Pharmacol. 56: 28.

23. Lindbohm M.L; Taskinen H.; Kyyronen P.; Sallmen M. Anttila A. and Hamminki K. (1992): Effects of prenatal occupational exposure to solvents and lead on spontaneous abortion. Scand. J. Work Environ.Helath.18: 37.

24. Lockitch G. (1993): Perspectives on lead toxicity. Clin. Biochem. 26: 371.

25. Mattison D.R. (1983): The mechanism of action of reproductive toxins. Am. J. Ind. Med.4: 65.

26. Mutiu-Turkoglu, U.; Ademoglu, E.; Ibrahimoglu, L., Aykac-Toker, G. and Uysa, E.M. (1998): Imbalance between lipid peroxidation and antioxidant status in pre-eclampsia. Gynecol. Obstet. Invest. 46: 37.

27. Ohruvall, M.; Tengblad, S.and Vessby, B. (1993): Lower Tochopherol serum levels in subjects with abdominal adiposity. J. Int. Med. 234: 53-60.

28. Perazella, M.A.(1996): Lead and the kidney, hypertension, and gout. Conn. Med. 60: 521.

29. Rao, G.N. and Berk, B.C. (1992): Active oxygen species stimulate vascular smooth muscle cell growth and proto-oncogen expression. Circ. Res. 70: 593-9.

30. Recknor, J.C, Reigar, R.J.; Darden, P.M.; Goyer, R.A.; Olden, K. and Richardson, M.C. (1997): Prenatal care and infant lead exposure J. Pediatr. 130: 123.

31. Richter. J; Hajek, Z.; Pfeifer, I. and Subrt, P. (1997): Relation of metal and lysozyme levels in the placenta of women with interutrine fetal growth retardation. Ceska Gynekol. 62: 3- 117.

32. Rimm, E.B.; Stampfer, M.J., Ascheris, A. Giovannucci E, Colditz G.A. and Willett W.C. (1993): Vitamin E consumption and the risk of coronary disease in men. Eng. J. Med. 328-1450.

33. Sharara, F.I.; David, B.; Seifer, D.B.; Jodi A. and Flows J.A. (1998): Environmental toxicants and female reproduction. Fertil steril. 70: 613.

34. Silbergeld E. (1991): Lead in bone Implication for toxicology during pregnancy and lactation. Environ. Health perspect. 91: 63 .

35. Stratta, P.; Canavese, C.; Porcu M., Dogliani M.; Todros T.; Garbo E.; Belliardo F.; Maina A.; Marazio, L. and Zonca M. (1994): Vitamin E supplementation in preeclampsia. Gynecol. Obstet. Invest.37: 246.

36. Uotila, J.T.; Tuimala R.J.; Aarnio T.M.; Pyykko K.A. and Ahotupa M.O. (2003): Findings on lipid peroxidation and antioxidant function in hypertensive complications of pregnancy. Br. J. Obstet. Gynecol. 100: 270.

37. Vaziri, N.D., Ding Y, Niz, and Gonick, HC. (2002): Altered nitric oxide metabolism and increased oxygen free radical activity in lead induced hypertension: effect of Lazaroid therapy. 52: 1042.

38. Von Mandach, U.; Huch R., and Huch. A (1993): Maternal and Cord serum vitamin E levels in normal and abnormal pregnancy Int. J. Vitam Nutr. Res. 63: 26.

39. Watson, R.R. and Leonard, T.K. (1986): Selenium and vitamins $\mathrm{A}, \mathrm{E}$ and $\mathrm{C}$. nutrients with cancer prevention. J. Am. Medical association. 505 - 510.

40. Watson R.R. (1990): Drugs of abuse and immune function. Press, Inc. Boca Raton, Florida.

41. Watson, R.R. and Peiro, T.M. (1982): Cellular immune response, corticosteroid levels and resistance to listeria monocytogenes and murine leukaemia in mice fed a high vit. E diet. Annals of the New York Academy of Sciences. 393: 205-210.

42. West, W.L.; Knight, E.M. and Edwards, C.H: Manning M. (2004): Maternal low level lead and pregnancy outcomes. J. Nutr 124: $981 \mathrm{~s}$. 


\section{تأخر نمو الجنين و العلاقة بين كل من مستوي الرصاص ومضادات الأكسدة و ارتفاع ضغط العامة لين في في دم الأم الحامل}

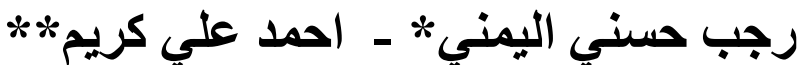

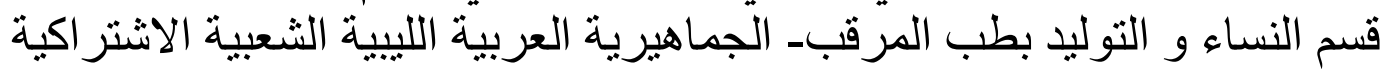

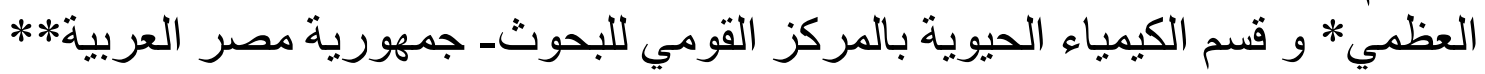

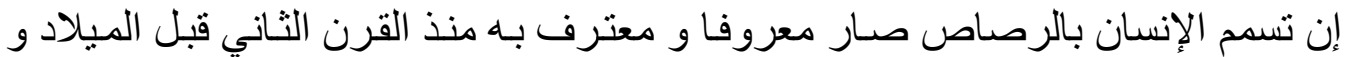

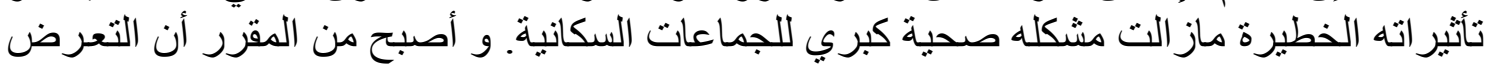

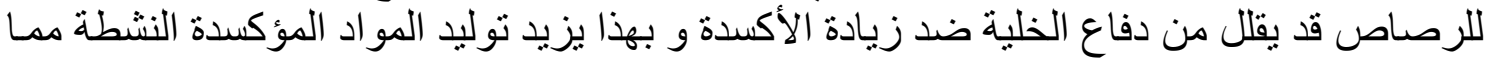

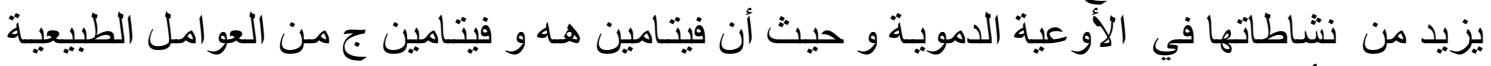

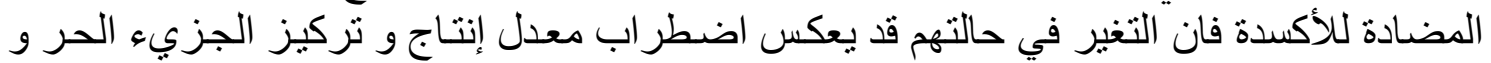

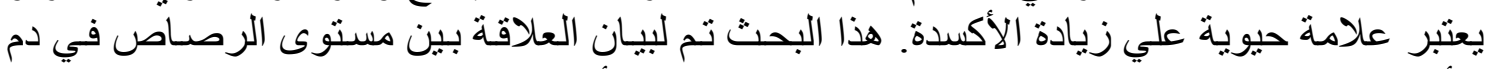

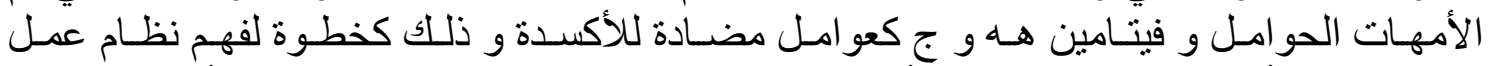

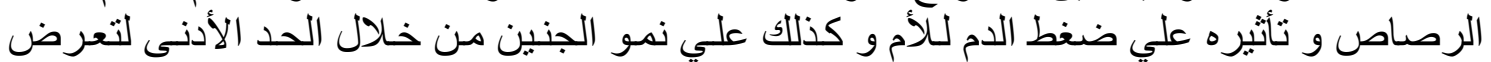

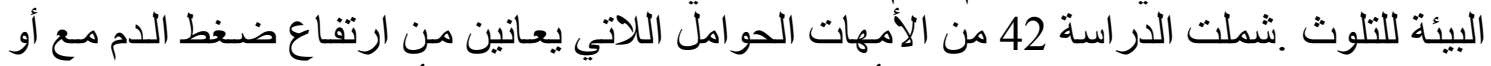

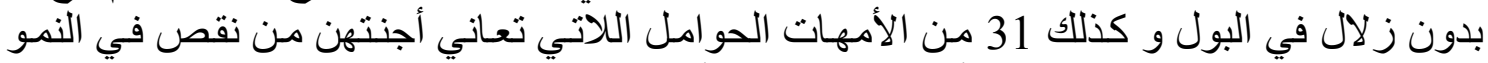

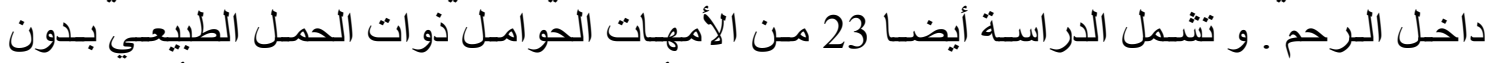

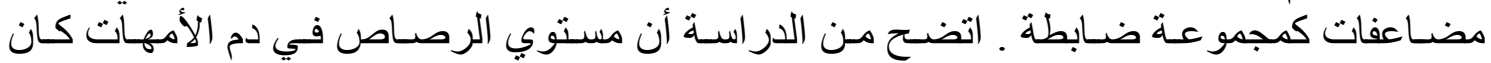

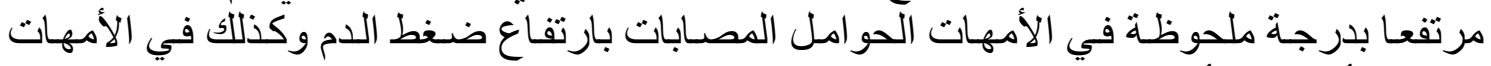

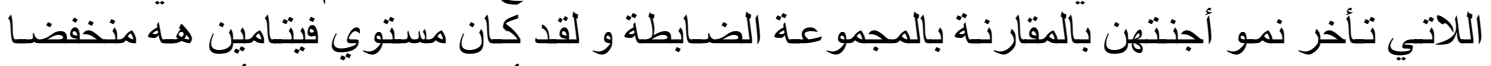

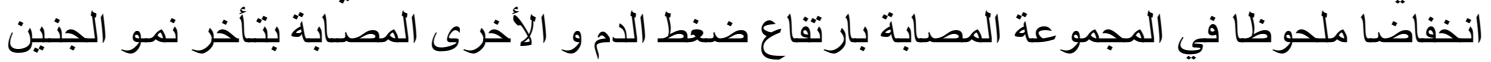

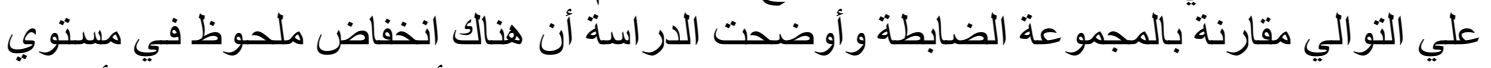

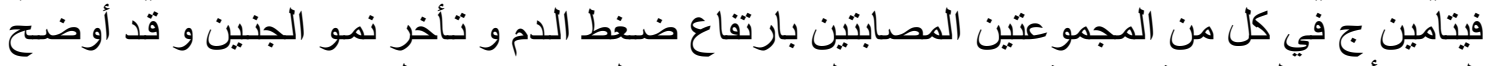

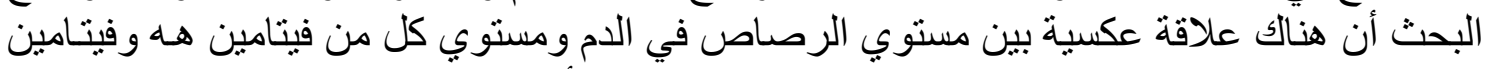

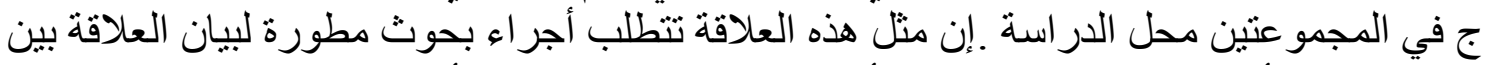

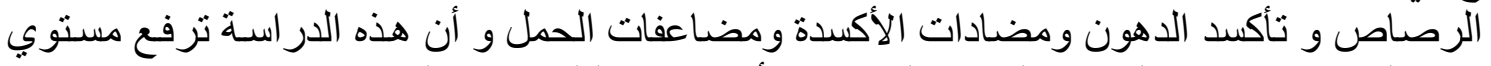

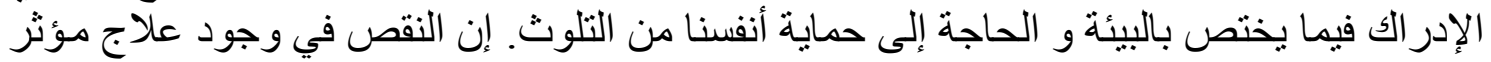

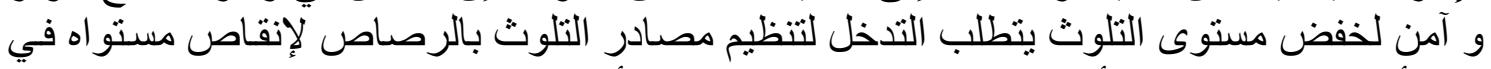

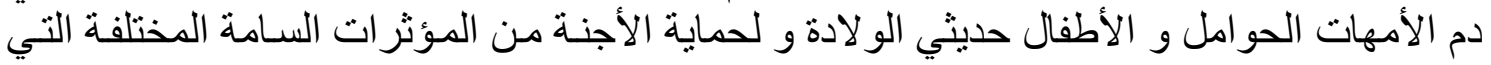

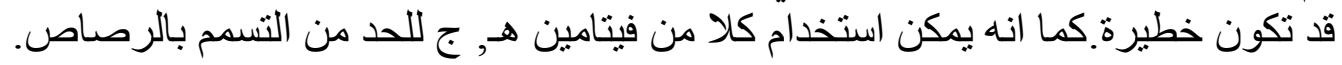

